\title{
Validation of the Korean Version of Attitudes Toward Motherhood Scale (AToM) in Pregnant Women
}

\author{
Hae-Mi Kim¹, Su-Kyoung Kang ${ }^{2}$ \\ Researcher, Sesalmaul Research Center, Gachon University, Seongnam, Korea ${ }^{1}$ \\ 임산부를 대상으로 한 한국판 어머니됨에 대한 \\ 역기능적 태도 척도(AToM)의 타당화 연구 \\ 김해미 ${ }^{1}$, 강수경 ${ }^{2}$ \\ 가천대학교 세살마을연구원 연구원 ${ }^{1}$, 가천대학교 유아교육학과 조교수2
}

Assistant Professor, Department of Early Childhood Education, Gachon University, Seongnam, Korea ${ }^{2}$

\begin{abstract}
Objectives: The purpose of this study was to verify the validity and reliability of Sockol's Attitudes Towards Motherhood Scale (AToM).

Methods: The subjects of this study were 534 pregnant women. The factor structure, reliability and validity of the AToM scale were examined, and SPSS 23.0 and Mplus 7.4 were used for all data analyses.

Results: The results of exploratory factor analysis revealed that 12-items were composed of 3-factor structure (beliefs related to others' judgments, beliefs related to maternal responsibility, beliefs related to maternal role idealization). The 12-items were found to be significant correlations among items and the reliability coefficient was .86 . The results of the confirmatory factor analysis showed that the 3-factor model and the factor loadings were found to be appropriate. Validity analysis showed that general dysfunctional attitudes, pregnancy stress, happiness, and AToM had significant correlations, so criterion validity were verified.

Conclusion: Based on the results of this study, we discussed the application of the AToM scale and implications for future research.
\end{abstract}

Keywords: attitudes towards motherhood scale, validity, pregnant women

\section{Introduction}

임신이란 여성의 삶을 크게 바꾸는 인생의 중요한 사건으로, 이때 여성은 한 개인에서 어머니로서의 정체성 변화를 경험한 다. 어머니로서의 정체성은 단순히 생득적인 것이 아니고 문 화적, 개인적 경험에 의해 학습되어지고 어머니란 가치에 대 한 인식과 태도 등으로 발달되는 것으로(Page, Combs-Orme,

Corresponding Author: Su-Kyoung Kang, Assistant Professor, Department of Early Childhood Education, Gachon University, 1342, Seongnam-daero, Sujeong-gu, Seongnam, Korea

E-mail: skkang-01@hanmail.net
\& Cain, 2007), 국외에서는 'motherhood', 'mothering' 등으로 표 현하고, 국내에서는 '어머니됨’으로 번역하여 사용한다. 최근 저출산 문제가 심각해지고 있는 상황에서 결혼과 출산을 개인 의 선택권으로 인식하면서(Y. R. Kim, 2009), 출산율에 미치는 영향으로 어머니됨에 대한 태도나 인식과 관련된 연구가 활발 히 진행되고 있다. 어머니됨에 대한 태도는 자녀를 임신한 순 간부터 시작되는 것으로, 이 태도가 임신기와 출산 이후 임산

(C)The Korean Association of Child Studies

This is an Open Access article distributed under the terms of the Creative Commons Attribution Non-Commercial License (http:// creativecommons.org/licenses/by-nc/4.0) which permits unrestricted noncommercial use, distribution, and reproduction in any medium, provided the original work is properly cited. 
부의 정서적 상태뿐만 아니라 자녀와의 관계에까지 중요한 영 향을 준다(E. H. Kim, Rhee, Lee, Kim, \& Doh, 2017).

특히 어머니됨에 대한 태도가 부정적인 경우 임산부의 스 트레스와 우울 및 불안 등에 중요한 영향을 미치고(Sockol, Epperson, \& Barber, 2014), 이는 출산 후 아이와의 애착이나 양육태도에 영향을 미치게 되며(Woolhouse, Gartland, Perlen, Donath, \& Brown, 2014) 이후 아이 발달에도 문제를 일으킬 수 있다. 여성은 이러한 어머니됨 과정에서 임신과 양육에 관 련된 상황들을 특정한 방식의 인지적 틀에 맞추어 해석하고 행동하면서 적응하려고 하는데, 이는 사람들이 모든 상황을 해석할 때 특정한 인지적 틀에 맞추어 해석하고 행동한다는 인지이론(Beck, Blackwell, \& Clair Jr, 1985)과도 일치한다. 임신 기란 많은 신체적·환경적 변화로 인하여 스트레스에 노출되 는 상황으로, 이 시기 어머니됨에 대한 부정적인 태도와 같이 스트레스에 취약한 인지적 편향성을 가진 임산부들은 더욱 부 정적인 영향을 많이 받을 수 있다(Church, Brechman-Toussaint, $\&$ Hine, 2005). 즉 어머니됨에 대한 인지적 틀이 편향적이고, 역기능적으로 형성되면 임신기의 스트레스 상황을 더욱 부정 적으로 받아들일 것이고, 그에 따른 스트레스와 정서적 불편 감은 더욱 커진다. 선행연구에서는 이를 '어머니됨에 대한 역 기능적 태도'로 명명하였는데, 이는 “어머니는 반드시 어떠해 야한다.”, "좋은 어머니/나쁜 어머니는 어떠하다.” 등과 같은 어머니됨에 대한 강박적이고 편향적인 인식을 말한다(Sockol et al., 2014). 즉 어머니의 역할, 책임, 그에 대한 타인의 평가와 기대 등과 같이 어머니됨에 초점이 맞추어져있는 인지적 태도 를 뜻한다(Sockol et al., 2014). 구체적으로 어머니됨에 대한 역 기능적 태도의 의미를 살펴보면, "내가 실수하면 사람들이 내 가 나쁜 엄마라고 생각할 것이다.”, "내가 아이를 사랑한다면 나는 항상 아이와 함께 있고 싶어해야한다.” 등과 같이 항상 완벽히 아이를 보호해야하고, 그렇지 않으면 사람들이 자신을 비난할 것이고, 자신 또한 어머니가 될 자격이 없어지는 것이 라는 믿음과 그에 대한 자신의 평가가 포함되어 있다(Sockol et al., 2014).

외국에서는 이러한 어머니됨에 대한 역기능적 태도가 산후 우울을 예측하는 핵심적인 인지적 특징이라고 알려져 관련연 구가 최근 활발히 이루어지고 있다. 실제로 임신기 어머니됨 에 대한 역기능적 태도가 출산 후 우울에 유의한 영향을 미친 다는 결과가 보고되었다(Sockol \& Battle, 2015). 또한 어머니 됨에 대한 역기능적 태도는 어머니로서 자신에 대한 부정적인 평가를 내리게 하고, 이는 어머니로서의 능력에 대한 불안한 생각을 반복적으로 하게하여 궁극적으로 기분이 나빠지게 만
든다(Fonseca, Monteiro, \& Canavarro, 2018). Fonseca 등(2018) 은 이 과정을 경험회피로 설명하고 있는데, 어머니됨에 대한 역기능적 태도는 불안감을 불러오는 상황이나 경험을 의식적 으로 회피하게 만들어서 즉각적으로는 정서적 불편감을 피할 수 있도록 하지만, 궁극적인 문제해결을 위한 기회를 박탈하 기 때문에 장기적으로는 심리적 불편감을 더욱 증가시킨다고 보고하였다. 또한 어머니됨에 대한 역기능적 태도가 강한 임 산부는 아이가 태어났을 때 자신이 아이를 잘 키울 수 있을지, 사람들이 자신을 어떻게 대할지 등 걱정이 커서 임신기 스트 레스가 높아진다(Phillips, Sharpe, Matthey, \& Charles, 2010). 또 한 양육에 대한 방법을 주변 사람들에게 배워야하는데, 타인 에게 도움을 청하는 것은 자신의 부족함을 보여주는 것이라는 잘못된 신념으로 인해 주변에서 도움을 적절히 받지 못하고 (Sockol et al., 2014), 양육을 올바르게 수행할 기회를 잃어서 자 녀양육에 대한 자신감이 부족해진다. 따라서 어머니됨에 대한 역기능적 태도는 여성의 심리적 측면에 악영향을 미치고, 출 산 이후에 우울이나 불안감, 정서적 고통 등을 증가시킬 수 있 으므로 역기능적 태도를 감소시키기 위한 연구와 개입이 필요 하다.

어머니됨에 대한 역기능적 태도의 측정도구는 현재 국내 에는 전무한 실정이고, 국외를 중심으로 개발되었다. 국외에 서 흔히 쓰는 도구에는 Maternal Attitudes Questionnaire (MAQ; Warner, Appleby, Whitton, \& Faragher, 1997), Pregnancy Related Beliefs Questionnaire (PRBQ; Moorhead, Owens, \& Scott, 2003), Attitudes Towards Motherhood Scale (AToM; Sockol et al., 2014) 등이 있다. 이 중 가장 많이 쓰이는 도구로는 PRBQ가 있는데, 개발과정에서 너무 작은 샘플사이즈를 사용하였고, 54 개라는 많은 문항 수, 요인분석을 따로 하지 않아서 하위요인이 없다 는 등의 문제를 지니고 있다. 또한 문항 내용이 어머니의 역할 에 대한 기대, 몸의 변화에 대한 인식 등 '기대'와 '인식'만을 주 로 다루었다. MAQ는 출산 이후 어머니를 대상으로 개발한 것 으로, 임산부를 대상으로 이 척도를 사용한 연구(Sockol, 2008) 에서 신뢰도가 낮게 나타나 임산부를 대상으로 사용하기는 적 절하지 않다고 보여진다. 또한 이 척도의 하위요인은 어머니 됨에 대한 기대, 어머니로서의 자신에 대한 기대, 역할 갈등으 로 인한 기대에 초점이 맞추어져 있다. 이처럼 기존 척도들은 어머니됨에 대한 기대를 주로 측정하는데, 기대는 실제로 아 이를 출산했을 때의 상황이 자신이 예측한 것과 다를 경우에 만 산후우울과 정서적 불편감에 영향을 미치고, 부정적인 기 대를 했었는데 실제 출산 후의 상황이 기대보다 좋다면 오히 려 산후우울의 보호요인으로 작용할 수 있기 때문에 임신기의 
부정적인 기대가 무조건적으로 산후우울을 예측한다고 볼 수 없다(Thomason, Flynn, Himle, \& Volling, 2015). 따라서 보다 신뢰할 수 있는 척도를 개발하기 위해서는 문항 내용에 단순 한 기대가 아니라 어머니됨에 대한 신념과 그에 따른 자신의 평가 등을 포함시켜야 한다.

이와 같은 측면에서 $\mathrm{AToM}$ 은 다른 척도들과 차별화되었다 고 볼 수 있다. AToM척도는 어머니됨에 대한 태도를 측정한 것으로 어떠한 것에 대해서 좋아하거나 싫어하는 정도를 평 가함으로써 표현되는 심리적 경향성으로 정의된다(Eagly \& Chaiken, 2007). AToM척도는 이러한 태도의 관점에서 어머니 됨에 대해서 가지고 있는 신념에 따라 자신을 평가하는 영역 까지 모두 포괄하는 개념을 제시하였다. Sockol 등(2014)은 완 벽주의나 타인에 대한 과도한 의존 등을 평가하는 '일반적인 역기능적 태도' 척도를 어머니됨에 대한 내용으로 수정하고, "나는 내 아이를 돌보는 데 어려움이 없을 것이다."를 "나는 내 아이를 돌보는 데 어려움이 없어야만 한다.”로 수정하여 어머 니됨에 대한 단순한 기대를 신념과 태도에 대한 문항으로 수 정하였다. 또한 임산부와 만 2세 이하의 아이를 가진 어머니 들을 대상으로 인터뷰를 실시하여 총 62 개 문항을 구성하였 고, 이후 타당화 분석을 통해 최종 12 개 문항으로 척도를 개 발하였다. 이 척도는 다른 사람들의 판단에 대한 믿음(beliefs related to others' judgments), 어머니의 책임에 대한 믿음(beliefs related to maternal responsibility), 어머니의 역할 이상에 대한 믿음(beliefs related to maternal role idealization)의 3 개 하위요인 으로 구성되어있다. 다른 사람들의 판단에 대한 믿음은 "내가 실수하면 사람들은 내가 나쁜 엄마라고 생각할 것이다.”와 같 이 타인이 자신의 어머니됨을 이분법적으로 평가할 것이라는 믿음을 의미하고, 어머니의 책임에 대한 믿음은 "내가 아이를 사랑한다면 나는 항상 아이와 함께 있고 싶어해야한다.”와 같 이 어머니라면 가져야 할 완벽주의적인 행동에 대한 믿음을 뜻하며, 어머니의 역할 이상에 대한 믿음은 "엄마가 된 것에 대해 실망하는 것은 잘못이다.", "내가 엄마가 되는 것에 실패 하면, 나는 한 인간으로서 실패한 것이다.”와 같이 어머니됨에 대해 긍정적인 정서와 평가를 가져야만 한다는 믿음을 의미한 다. 즉 AToM척도는 다른 척도에 비해 산후에 생기는 여러 정 서적 문제들로 연결되는 임산부들의 인지적 취약성을 보다 더 잘 반영하고 있다고 볼 수 있다. 따라서 국내에서도 임산부들 의 정서적 문제를 예방할 수 있도록 어머니됨에 대한 역기능 적 태도를 측정할 수 있는 AToM 척도에 대한 타당화 연구를 시행할 필요가 있을 것이다.

본 연구에서는 $\mathrm{AToM}$ 척도의 준거타당도 검증을 위해서
어머니됨에 대한 태도와 상관이 높게 밝혀진 변인이면서 정 서적인 특성을 반영할 수 있는 일반적인 역기능적 태도와 임 신기 스트레스, 행복감을 준거변인으로 설정하였다. 일반적 인 역기능적 태도란 내재화 문제를 가진 이들의 인지적 특징 으로 대표되는 것으로, 완벽주의적이고 타인의 평가에 민감 하며, 타인에게 과도하게 의존하는 인지적 신념 및 태도를 의 미한다(Beck, 1972). 이런 태도를 지닌 이들의 인지적 틀은 부 적절한 자아상과 현재 및 미래에 대한 부정적인 인식, 실패 등에 편향적으로 초점이 맞추어져 있다(de Graaf, Roelofs, \& Huibers, 2009). 선행연구에서는 이러한 인지적 특성과 임신기 어머니됨에 대한 역기능적 태도가 동일한 인지적 편향을 기 저로 하기 때문에 두 변인 간에 높은 상관관계가 있음을 밝혔 다(Fonseca et al., 2018). 또한 AToM에서 측정하고 있는 어머 니됨에 대한 완벽주의적이고 자기평가적인 태도는 완벽한 어 머니가 되어야한다는 강박관념을 갖게 만드는데(Sockol et al., 2014), 이는 임산부로 하여금 태아의 현재 상태와 미래에 대한 불안감과 임산부 자신의 상태에 대한 스트레스를 증폭시킬 수 있다. 임신이라는 스트레스 요인은 그 자체로 스트레스로 다 가오는 것이 아니라 받아들이는 사람의 특정한 인지적 신념에 따라서 정서적 고통이 달라지므로(Milgrom, Martin, \& Negri, 1999), 같은 임신상태라도 역기능적인 태도를 지닌 임산부에 게는 더 큰 스트레스로 다가올 수 있어 어머니됨에 대한 역기 능적 태도와 임신기 스트레스가 유의한 상관관계가 있으리라 예측할 수 있다. 뿐만 아니라 어머니됨에 대한 역기능적 태도 는 임산부의 행복감에도 영향을 미칠 수 있는데, 편향된 인지 적 틀로 인해 자신과 세상의 부정적인 면에 집중하여 스트레 스 상황을 더 크게 받아들이고(de Graaf et al., 2009), 그로 인한 우울 및 불안과 같은 정서적 불편감이 궁극적으로 개인의 행 복감을 낮출 것이다(Church et al., 2005).

국외에서는 이미 어머니됨에 대한 역기능적 태도가 산후우 울과 정서적 고통에 유의한 영향을 미친다는 것이 밝혀졌고, 산후우울에 영향을 미치는 인지적 편향을 바꾸려는 인지치료 적 개입을 통해서 산후우울의 발병과 진행을 늦추려는 시도를 적극적으로 하고 있다(Dimidjian et al., 2016). 하지만 국내에는 어머니됨에 대한 역기능적 태도를 측정할 수 있는 척도가 전 무한 실정으로 국내에서도 관련 척도의 타당화연구를 진행하 여 어머니됨의 태도를 측정하고 관련 프로그램을 개발할 필요 가 있다. 즉 역기능적 태도의 측정을 통해 산후우울에 인지적 취약성을 지닌 사람들을 대상으로 임신기부터 출산 이후까지 정서적으로 건강하기 위해 예방적 차원의 인지적 개입이 필요 할 것으로 보인다. 따라서 본 연구에서는 문항분석과 탐색적 
요인분석을 통해 한국 임산부에게 적합한 요인구조를 확인하 고, 확인적 요인분석, 신뢰도 검증을 통해 탐색된 요인구조 모 형의 적합도를 분석하며 준거타당도를 검증해 AToM 척도를 한국판으로 타당화하는 것을 목적으로 한다. 이러한 타당화 연구를 통해 임산부 및 영아기 어머니의 정신 건강 개선에서 의 적용가능성을 높일 것이다.

\section{연구문제 1}

한국판 어머니됨에 대한 역기능적 태도 척도(AToM)의 신뢰 도와 타당도는 어떠한가?

1-1. 한국판 어머니됨에 대한 역기능적 태도 척도(AToM)의 문항분석 결과는 어떠한가?

1-2. 한국판 어머니됨에 대한 역기능적 태도 척도(AToM)의 탐색적 요인분석 결과는 어떠한가?

1-3. 한국판 어머니됨에 대한 역기능적 태도 척도(AToM)의 신뢰도는 어떠한가?

1-4. 한국판 어머니됨에 대한 역기능적 태도 척도(AToM) 의 확인적 요인분석 결과는 어떠한가?

1-5. 한국판 어머니됨에 대한 역기능적 태도 척도(AToM)의 준거타당도는 어떠한가?

\section{Methods}

\section{연구대상}

본 연구를 위해 서울·경기 지역 자치구의 임산부교육에 참가 한 임산부 534 명을 대상으로 설문을 실시하였다. 자녀수가 어 머니됨에 대한 태도나 임신기 스트레스에 유의한 영향을 미칠 수 있기 때문에 이를 통제하기 위하여 첫째아를 가진 임산부 만을 연구대상으로 선정하였다. 탐색적 요인분석과 확인적 요 인분석을 다른 표본으로 하기 위하여 표본을 1,2 로 나누어 조 사하였다. 연구대상자의 인구통계학적 특징은 Table 1에 제시 되었다. 연구대상 연령은 30 세 미만이 1 차 표본과 2 차 표본 각 각 38명(14.2\%), 54명(20.2\%), 30세 이상에서 40세 미만이 219 명(82.0), 208명(77.9\%), 40세 이상이 10명(3.7\%), 3명(1.1\%)
으로 두 표본 모두 대다수가 30 대였고, 최종학력은 고졸이 각 각 41 명(15.4\%), 32명(12.0\%), 대졸이 145명(54.3\%), 185명 (69.3\%), 대학원졸이 80명(30.0\%), 50명(18.7\%)로 모든 표본 에서 대졸이 가장 많았다. 월평균 가구소득은 300 만원 미만 이 각각 27명(10.1\%), 26명(9.7\%), 300만원 이상에서 400만원 미만이 40명(15.0\%), 60명(22.5\%), 400만원 이상에서 500만 원 미만이 58명(21.7\%), 39명(14.6\%), 500만원 이상에서 600 만원 미만이 51명(19.1\%), 47명(17.6\%), 600만원 이상이 89 명(33.3\%), 91명(34.1\%)으로 나타났고, 취업여부는 취업자가 각각 129 명(48.3\%), 122 명(45.7\%), 육아휴직중인 자가 52명 (19.5\%), 54명(20.2\%), 비취업자가 86명(32.2\%), 89명(33.3\%) 이었다. 임신주수는 10 주 미만이 2명 $(0.7 \%), 5$ 명(1.9\%), 10 주 이상 20주 미만이 36명(13.5\%), 42명(15.7\%), 20주 이상 30주 미만이 115 명(43.1\%), 118 명(44.2\%), 30주 이상 40 주 미만이 113 명(42.3\%), 100명(37.5\%)이다.

\section{측정도구}

\section{어머니됨에 대한 역기능적 태도}

$\mathrm{AToM}$ 은 어머니됨에 대한 역기능적 태도를 측정하기 위해 Sockol 등(2014)이 개발한 척도이다. 이 척도는 3 개의 하위요 인으로 이루어져 있는데 '다른 사람들의 판단에 대한 믿음' 4 문항, '어머니의 책임에 대한 믿음' 4 문항, '어머니의 역할 이상 에 대한 믿음 4 문항의 총 12 문항으로 구성되어 있다. 다른 사 람들의 판단에 대한 믿음은 "아이가 울면 사람들은 내가 아이 를 적절히 돌볼 수 없다고 생각할 것이다.”와 같은 문항들로 구성되어있고, 어머니의 책임에 대한 믿음은 "나는 내 아이에 게 더 헌신적이어야 한다.”와 같은 문항, 어머니의 역할 이상 에 대한 믿음은 "내 아이에 대해 복합적인 감정을 갖는 것은 잘못된 것이다.”와 같은 문항들로 구성되어있다. 이와 같이 문 항의 내용이 역기능적인 태도를 표현하는 것이라서 의미의 정 확한 표현을 위하여 한국판으로 번역할 때 어머니됨에 대한 역기능적 태도라고 하였다. 각 문항은 전혀 아니다(1점)에서 매우 그렇다(6점)로 6점 Likert척도로 되어있고, 점수가 높을 수록 어머니됨에 대한 역기능적인 태도가 높다고 볼 수 있다. Sockol 등(2014)의 연구에서 신뢰도계수는 전체가 .81이었고, 하위요인은 .74 .82였다. 본 연구에서의 신뢰도계수는 전체 가 .86 , 다른 사람들의 판단에 대한 믿음은 87 , 어머니의 책임 에 대한 믿음은 .82 , 어머니의 역할 이상에 대한 믿음은 .79 로 나타났다. 
Table 1

Demographic Characteristics of Subjects

\begin{tabular}{|c|c|c|c|}
\hline & \multirow[b]{2}{*}{ Variable } & \multicolumn{2}{|l|}{ Frequency (\%) } \\
\hline & & 1st sample & 2nd sample \\
\hline \multirow[t]{3}{*}{ Age } & 21-29 age & $38(14.2)$ & $54(20.2)$ \\
\hline & 30-39 age & $219(82.0)$ & 208 ( 77.9) \\
\hline & Over the age of 40 & $10(3.7)$ & $3(1.1)$ \\
\hline \multirow[t]{2}{*}{ Academic background } & High school & $41(15.4)$ & $32(12.0)$ \\
\hline & Postgraduate school & $80(30.0)$ & $50(18.7)$ \\
\hline \multirow[t]{3}{*}{ Monthly household income } & Less than 300 (10,000 won) & $27(10.1)$ & $26(9.7)$ \\
\hline & $300-399$ & $40(15.0)$ & $60(22.5)$ \\
\hline & $400-499$ & $58(21.7)$ & $39(14.6)$ \\
\hline \multirow[t]{3}{*}{ Employment status } & Employment & $129(48.3)$ & $122(45.7)$ \\
\hline & Unemployment & $52(19.5)$ & $54(20.2)$ \\
\hline & Parental leave & $86(32.2)$ & $89(33.3)$ \\
\hline \multirow[t]{4}{*}{ Gestational age (weeks) } & Less than 10 & $2(0.7)$ & $5(1.9)$ \\
\hline & $10-19$ & $36(13.5)$ & $42(15.7)$ \\
\hline & $20-29$ & $115(43.1)$ & $118(44.2)$ \\
\hline & $30-40$ & $113(42.3)$ & $100(37.5)$ \\
\hline Total & & $267(100.0)$ & $267(100.0)$ \\
\hline
\end{tabular}

Note. some differences in the total number of cases exist.

\section{일반적인 역기능적 태도}

일반적인 상황에서의 역기능적 태도를 측정하기 위해 $\mathrm{de}$ Graaf 등(2009)이 개발한 Dysfunctional Attitudes in the General Population (DAGP) 척도를 연구자가 직접 번역하여 사용하였 다. 이 척도는 두 개의 하위요인으로 이루어져 있는데, '완벽주 의/수행평가' 11 문항, '의존' 6 문항의 총 17 개의 문항으로 구성 되어있다. 완벽주의/수행평가는 "만약 잘생기고, 똑똑하며, 부 유하고 창의적이지 않다면 행복하기 어렵다.”와 같이 완벽함 에 대한 강박적 사고를 의미하는 문항으로 구성되고, 의존은 "중요한 사람들로부터 인정받지 못하는 것은 나에게 매우 두 려운 일이다.”와 같이 타인의 평가에 민감하며 타인의 인정을 과도하게 추구하는 내용들의 문항들로 구성되어있다. 각 문항 은 전혀 아니다(1점)에서 매우 그렇다(7점)의 7점 Likert 척도 로 평정하도록 되어 있으며 점수가 높을수록 일반적인 역기능 적 신념이 강하다는 것을 의미한다. de Graaf 등(2009)의 연구
에서 전체 신뢰도 계수는 .90이며, 완벽주의/ 수행평가는 .81, 의존은 .91로 나타났고, 본 연구에서는 전체 신뢰도 계수는 .92 이며, 완벽주의/수행평가와 의존 모두 .90으로 나타났다.

\section{임신기 스트레스}

임산부의 스트레스를 측정하기 위해서 Ahn (1983)이 개발한 임신 스트레스 척도를 사용하였다. 본 척도는 3 가지 하위요인 으로 '태아와 관련된 스트레스' 9문항, '배우자와 관련된 스트 레스' 6문항, '임부와 관련된 스트레스' 11 문항의 총 26문항으 로 이루어져있다. 태아와 관련된 스트레스에는 "아기가 태어 나면 잘 양육할 수 있을지 걱정된다.”와 같은 문항, 배우자와 관련된 스트레스는 "남편의 수입으로 아기 양육비를 충분히 감당할 수 있을지 걱정이다.”와 같은 문항, 임부와 관련된 스 트레스는 "분만 시에 경험하게 될 동통이나 난산, 수술 때문에 걱정이 된다.”와 같은 문항들로 구성되어있다. 각 문항은 전혀 
아니다(1점)에서 매우 그렇다(5점)의 5점 Likert 척도로 이루어 졌으며, 점수가 높을수록 임산부가 느끼는 임신기 스트레스가 높은 것을 의미한다. Ahn (1983)의 연구에서 전체 신뢰도계수 는 .84였고, 본 연구의 전체 신뢰도계수는 .91, 태아와 관련된 스트레스는 .85, 배우자와 관련된 스트레스는 .78, 임부와 관 련된 스트레스는 .86으로 나타났다.

\section{행복감}

행복감을 측정하기 위해서 Hills와 Argyle (2002)의 The Oxford Happiness Questionnaire (OHQ) 척도를 Choi (2002)가 한국어 로 번역한 것을 사용하였다. 본 척도는 삶의 만족도, 긍정정서 에 대한 강도와 빈도, 우울이나 불안과 같은 부정정서의 부재 등을 포함한 문항들로 구성되어있다. 본 척도는 단일요인으 로 총 29문항이고, "나는 대부분의 것들이 재밌다.", "나는 다 른 사람들에 대해 대단한 관심이 있다.”와 같은 문항들로 구성 되어있다. 각 문항은 전혀 아니다(1점)에서 매우 그렇다(6점) 의 6점 Likert척도로 되어있고, 점수가 높을수록 행복감이 높 은 것으로 해석된다. Choi (2002)의 연구에서의 신뢰도계수는 .92 였으며 본 연구에서의 신뢰도계수도. 92 로 나타났다.

\section{연구절차}

AToM의 타당화 연구를 위해 발달심리학과 유아교육을 전공 하고 해외체류 경험이 있는 연구자가 번역하고 영어전공 교수 1 인이 수정하여 1 차 번역본을 완성하고, 영어전공 교수가 1 차 번역본과 원문이 일치하는지 확인하였다. 이를 통해 부적합하 다고 판단된 문항들을 찾아내고 영어전공 교수와 협의하여 번 역-역번역 과정을 거쳐 최종 번역을 마쳤다. 번역과정에서 역 번역된 검사지와 원문을 대조하면서 문항의 의미를 왜곡하지 않도록 수정작업이 이루어졌으며, 최종 번역된 문항내용에 대 해서 임산부 관련 연구경험이 많은 교수 2 인으로부터 내용타 당도를 확인받았다. 이 과정에서 AToM 척도가 어머니됨에 대 한 ‘역기능적인' 태도에 초점이 맞추어진 도구이기 때문에 한 국어로 번역할 때 보다 의미를 정확히 하기 위하여 어머니됨 에 대한 역기능적 태도로 번역하기로 결정하였다. 문항이해도 를 확인하기 위해 2018년 7월에 45명의 임산부를 대상으로 예 비조사를 실시하였고, 문항이해도 평균이 5점 만점에 4점 이 상으로 문항이해도에 문제가 없음이 확인되었다.

본 조사는 2018년 8월부터 12월까지 G대학이 주최하는 서 울-경기지역의 임산부 교육에 참여한 임산부를 대상으로 실
시하였다. 설문지는 서울·경기의 총 21 개 자치구의 보건소 및 육아종합지원센터에 배부하였으며, 교육효과 방지를 위해 교육이 시작되기 전에 실시하였다. 임산부에게 연구의 취지 를 설명하여 연구 참여 및 개인정보제공 동의서를 받았다. 총 551 부를 수거하였으나 불성실하게 대답한 17 부를 제외하고 최종적으로 534 부가 분석에 사용되었다.

\section{자료분석}

먼저 총 534 개의 케이스를 전후 반분법으로 나누어 1차 표본 인 267개로 문항분석, 탐색적 요인분석과 신뢰도 분석을 실시 하였고, 2차 표본인 267개로 확인적 요인분석을 하였으며, 전 체 표본인 534 개를 대상으로 준거타당도를 분석하였다. 자료 는 통계 프로그램 SPSS 23.0과 M-plus 7.4 (Muthén \& Muthén, 2015)를 이용하여 분석하였다. 모형의 적합성은 X2 검증과 표 본 크기의 영향을 덜 받는 CFI, TLI와 RMSEA, SRMR을 사용 하여 검증하였다. CFI와 TLI는 .90이상이면, SRMR과 RMSEA 는 .08 이하면 모형의 적합도가 좋은 것으로 본다(Kline, 2015). 신뢰도 검증을 위해 문항내적합치도(Cronbach's $\alpha$ )와 반분신 뢰도값을 산출하였고, 준거타당도를 보기 위하여 어머니됨의 역기능적 신념의 관련 변인인 일반적 역기능적 신념, 행복감, 임신기 스트레스 척도와의 Pearson상관분석을 실시하였다.

\section{Results}

\section{문항분석}

어머니됨에 대한 역기능적 태도 문항들의 적절성을 확인하 기 위해 문항분석을 실시하였다. 문항분석 과정은 2 단계를 거 쳤다. 첫째는 기술통계분석을 통해서 각 문항의 평균과 왜도 및 첨도를 산출해서 극단적인 평균 값을 가진 것이 없는지, 정 규성을 위배하는 왜도, 첨도 값이 있는지를 검토하였다. 6점 척도로 구성된 검사에서 문항평균이 1.5 점 이하이거나 5.5점 이상인 문항을 적절치 않은 것으로 판단한다(Frisbie \& $\mathrm{Ebel}$, 1972). 왜도는 3 이상, 첨도는 10 이상일 때 정규성을 위배하는 것으로 판단한다. 둘째, 문항-총점 간 상관과 문항 간 상관을 산출하여 문항의 적절성을 검토하였다. 문항-총점 간 상관은 .3 이하, 문항 간 상관은 .7 이상을 기준으로 적절하지 않은 것 으로 보았다(Frisbie \& Ebel, 1972). 문항분석의 결과는 Table 2 에 나타나있다. 위의 기준들로 문항의 적절성을 검토한 결과, 
Table 2

Correlations Among AToM Items and Descriptive Statistics

\begin{tabular}{|c|c|c|c|c|c|c|c|c|c|c|c|c|}
\hline & 1 & 2 & 3 & 4 & 5 & 6 & 7 & 8 & 9 & 10 & 11 & 12 \\
\hline Item1 & - & & & & & & & & & & & \\
\hline Item2 & $.65^{* *}$ & - & & & & & & & & & & \\
\hline Item3 & $.60^{* *}$ & $.60^{* *}$ & - & & & & & & & & & \\
\hline Item4 & $.59^{* *}$ & $.53^{* *}$ & $.63^{* *}$ & - & & & & & & & & \\
\hline Item5 & $.21^{* *}$ & $.16^{* *}$ & $.19^{* *}$ & $.25^{* *}$ & - & & & & & & & \\
\hline Item6 & $.26^{* *}$ & $.24^{* *}$ & $.24^{* *}$ & $.24^{* *}$ & $.64^{* *}$ & - & & & & & & \\
\hline Item7 & $.19^{* *}$ & $.14^{*}$ & $.19^{* *}$ & $.22^{* *}$ & $.54^{* *}$ & $.54^{* *}$ & - & & & & & \\
\hline Item8 & $.19^{* *}$ & $.14^{*}$ & $.19^{* *}$ & $.21^{* *}$ & $.52^{* *}$ & $.47^{* *}$ & $.46^{* *}$ & - & & & & \\
\hline Item9 & $.22^{* *}$ & $.27^{* *}$ & $.20^{* *}$ & $.19^{* *}$ & $.28^{* *}$ & $.34^{* *}$ & $.30^{* *}$ & $.33^{* *}$ & - & & & \\
\hline Item 10 & $.29^{* *}$ & $.31^{* *}$ & $.25^{* *}$ & $.38^{* *}$ & $.34^{* *}$ & $.33^{* *}$ & $.33^{* *}$ & $.33^{* *}$ & $.45^{* *}$ & - & & \\
\hline Item 11 & $.18^{* *}$ & $.21^{* *}$ & $.17^{* *}$ & $.21^{* *}$ & $.33^{* *}$ & $.30^{* *}$ & $.33^{* *}$ & $.28^{* *}$ & $.57^{* *}$ & $.63^{* *}$ & - & \\
\hline Item 12 & $.39^{* *}$ & $.42^{* *}$ & $.38^{* *}$ & $.41^{* *}$ & $.25^{* *}$ & $.29^{* *}$ & $.27^{* *}$ & $.18^{* *}$ & $.35^{* *}$ & $.48^{* *}$ & $.41^{* *}$ & - \\
\hline Total & $.63^{* *}$ & $.62^{* *}$ & $.60^{* *}$ & $.62^{* *}$ & $.64^{* *}$ & $.66^{* *}$ & $.62^{* *}$ & $.58^{* *}$ & $.62^{* *}$ & $.68^{* *}$ & $.62^{* *}$ & $.62^{* *}$ \\
\hline $\bar{M}$ & 2.45 & 2.73 & 2.35 & 1.79 & 2.95 & 3.42 & 3.25 & 3.16 & 3.47 & 2.17 & 2.98 & 1.83 \\
\hline$S D$ & 1.25 & 1.29 & 1.17 & .95 & 1.24 & 1.19 & 1.45 & 1.29 & 1.44 & 1.13 & 1.32 & 1.06 \\
\hline Skewness & .45 & .24 & .56 & 1.13 & .21 & -.48 & .02 & -.03 & -.13 & .80 & .32 & 1.20 \\
\hline Kurtosis & -.94 & -.96 & -.49 & .69 & -.44 & -.37 & -.92 & -.68 & -.81 & .20 & -.45 & .66 \\
\hline
\end{tabular}

Note. $N=267$.

${ }^{*} p<.05 .{ }^{* *} p<.01$.

문항의 평균이 1.5 점 이하이거나 5.5점 이상인 문항이 없었고, 또한 문항-총점 상관이 .3이하이거나 문항 간 상관이 .7 이상 인 문항은 없는 것으로 나타났다. 따라서 문항 제거 없이 본 문 항 그대로 탐색적 요인분석을 실시하였다. 전체문항의 평균 은 1.79 3.47점으로 나타났고, 문항-총점 간 상관은 .58 .68, 문항 간 상관은.14 .65로 나타나 기준에 위배되는 값이 없는 것으로 나타났다.

\section{탐색적 요인분석}

어머니됨에 대한 역기능적 태도 척도의 구성요인을 확인하기 위하여 1차 표본을 대상으로 탐색적 요인분석을 실시하였다. 먼저 구형성 검정을 위해 Kaiser-Meyer-Olkin (KMO)와 Bartlett 검정을 실시하였는데, $\mathrm{KMO}$ 적합성 지수는 .849, Bartlett 검정 결과는 $\chi^{2}(66)=1404.401, p<.001$ 로 요인분석을 하기에 적 합한 자료로 확인되었다. 요인분석방법으로는 주축요인추출 (principal axis analysis) 방식과 사각회전법인 프로맥스(promax) 를 사용하였다. 요인수 결정을 위해 아이겐값과 누적분산비 율이 55-65\%가 되는 지점을 살펴보고, 스크리 검정(scree test) 결과도 확인하였다(Costello \& Osborne, 2005). 본 연구에서는
요인수를 지정하지 않고 요인분석을 하면 아이겐값이 1 을 넘 는 것이 3 요인으로 추출되고, 3 요인까지의 누적분산비율이 $60 \%$ 를 넘었으며, 스크리 검정 또한 4요인 앞에서 급격하게 꺾 여 원척도와 마찬가지로 3 요인이 적절한 것으로 판단되었다 (Figure 1). 또한 평행선 분석(parallel analysis)을 실시해 보다 정 확한 요인수를 결정하였다. 평행선 분석은 원자료의 아이겐 값과 무선자료의 아이겐값을 비교하는 기법으로(Horn, 1965), 보다 정확한 요인수를 결정하도록 돕는다(Hayton, Allen, \& Scarpello, 2004). 평행분석 결과, 요인의 실제 고유값이 평행 분석으로 추출한 95 백분위 고유값보다 작아지는 지점이 4 번 째 요인으로 나타나 요인의 수는 3 개로 설정하였다. 이후 요인 수를 3 개로 지정하고 프로맥스 회전 요인분석을 다시 실시하 였고, 분석결과 3 요인이 적절한 것으로 나타났다. 요인 1 의 초 기 아이겐값은 4.80 로 전체 변량의 $40.03 \%$ 를, 요인 2 의 초기 아이겐값은 1.97 로 전체 변량의 $16.48 \%$ 를 설명하였으며, 요 인 3의 초기 아이겐값은 1.26 로 전체 변량의 $10.51 \%$ 로 나타났 다. 프로맥스 회전을 한 후의 아이겐값은 요인 1 은 3.66 , 요인 2 는 3.40 , 요인 3 은 3.48 로 나타났다. 구조행렬의 아이겐값과 요인부하량 산출 결과는 Table 3에 나타나있다. 요인부하량의 적절성을 살펴보면 모든 문항의 요인부하량이 .40보다 크게 


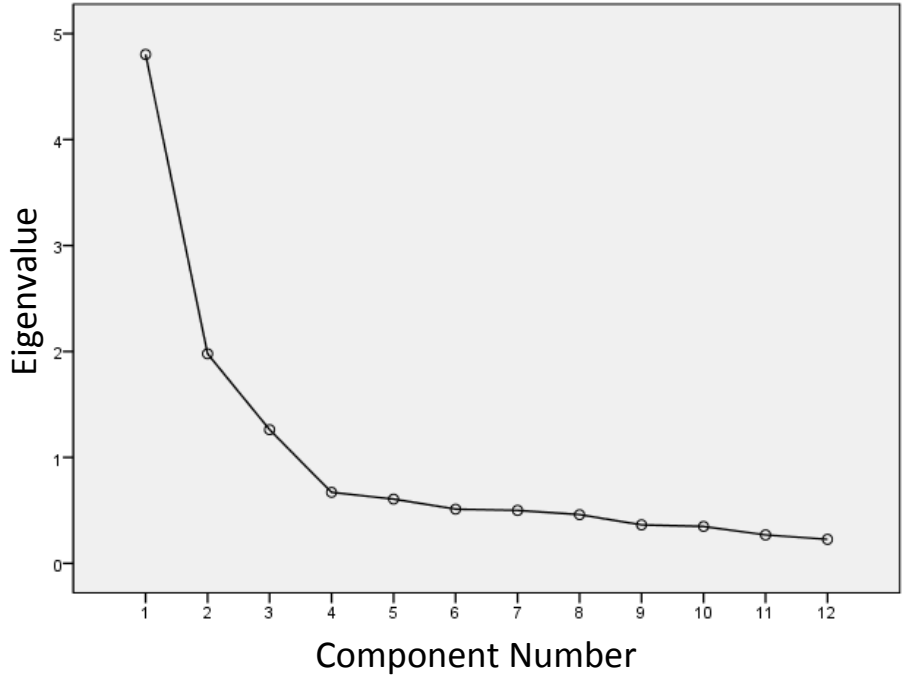

Figure 1. Scree chart.

Table 3

Factor Loading and Reliability

\begin{tabular}{|c|c|c|c|c|}
\hline \multirow{3}{*}{$\begin{array}{l}\text { Factor } \\
\text { Beliefs related to others' } \\
\text { judgments }\end{array}$} & \multirow{5}{*}{$\begin{array}{l}\text { Item } \\
\text { 1. If I make a mistake, people will think I am a bad mother. } \\
\text { 2. People will probably think less of me if I make parenting mistakes. } \\
\text { 3. If my baby is crying, people will think I cannot care for him/her properly. } \\
\text { 4. Seeking help with my baby from other people makes me feel incompetent. }\end{array}$} & \multicolumn{3}{|c|}{ Factor loading } \\
\hline & & .87 & .26 & .30 \\
\hline & & .85 & .20 & .35 \\
\hline & & .83 & .26 & .27 \\
\hline & & .80 & .29 & .34 \\
\hline \multirow{4}{*}{$\begin{array}{l}\text { Beliefs related to } \\
\text { maternal responsibility }\end{array}$} & 5. If I love my baby, I should want to be with him/her all the time. & .26 & .85 & .37 \\
\hline & 6. I should feel more devoted to my baby. & .31 & .82 & .39 \\
\hline & 7. I am the only person who can keep my baby safe. & .21 & .78 & .40 \\
\hline & 8. Good mothers always put their baby's needs first. & .21 & .74 & .35 \\
\hline \multirow{4}{*}{$\begin{array}{l}\text { Beliefs related to } \\
\text { maternal role idealization }\end{array}$} & 9. It is wrong to feel disappointed by motherhood. & .26 & .38 & .77 \\
\hline & 10. It is wrong to have mixed feelings about my baby. & .38 & .41 & .82 \\
\hline & 11. Negative feelings towards my baby are wrong. & .23 & .40 & .88 \\
\hline & 12. If I fail at motherhood, then I am a failure as a person. & .54 & .28 & .65 \\
\hline \multicolumn{2}{|l|}{ Initial eigenvalue } & 4.80 & 1.97 & 1.26 \\
\hline \multicolumn{2}{|l|}{ Rotated eigenvalue } & 3.66 & 3.40 & 3.48 \\
\hline \multicolumn{2}{|l|}{$95 \%$ tile eigenvalue } & 1.91 & 1.79 & 1.16 \\
\hline \multicolumn{2}{|l|}{ Variance $(\%)$} & 40.03 & 16.48 & 10.51 \\
\hline \multicolumn{2}{|l|}{ Cumulative variance $(\%)$} & & 56.51 & 67.03 \\
\hline \multicolumn{2}{|c|}{ Internal consistency reliability } & .86 & .81 & .78 \\
\hline \multicolumn{2}{|l|}{ Half-split reliability } & .80 & .80 & .83 \\
\hline
\end{tabular}

Note. $N=267$.

나타나서 적절성 기준에 부합하는 것으로 나타났다(Floyd \& Widaman, 1995).

각 요인에 포함된 문항들을 살펴보면, 요인 1 은 원척도와 마 찬가지로 1-4번 문항이 추출되었으며 다른 사람들의 판단에 대한 믿음을 나타내는 내용으로 구성되었다. 요인2도 원척도
와 마찬가지로 문항 5-8번 문항이 추출되어 어머니의 책임에 대한 믿음에 대한 내용으로 구성되었고, 요인 3 또한 원척도와 마찬가지로 문항 9-12번 문항이 추출되어 어머니의 역할 이상 에 대한 믿음을 나타내는 내용으로 구성되었다. 


\section{신뢰도 분석}

문항분석과 탐색적 요인분석을 통해 확인된 12 개의 문항에 대해 1 차 표본을 이용해서 신뢰도 분석을 실시하였고, 결과 는 Table 3 에 제시하였다. 12 개 문항 전체에 대한 내적합치도 (Cronbach's $\alpha$ )는 .86으로 좋은 신뢰도를 나타냈으며, 각 요인 의 내적합치도(Cronbach's $\alpha$ )는 요인 1이 .86이고, 요인 2가 .81 , 요인 3은 .78로 모두 우수한 신뢰도를 보여 각 하위요인과 모든 문항들이 전반적으로 안정적인 개념임을 확인하였다. 반 분 신뢰도 또한 요인 1 은 .80 , 요인 2 는 .80 , 요인 3 은 .83 로 우 수한 신뢰도를 보였다.

\section{확인적 요인분석}

문항분석과 탐색적 요인분석을 통해 검증된 원척도와 동일 한 12 개의 문항에 대해 2차 표본을 이용해서 확인적 요인분 석을 실시하였다. 측정모델의 적합도 평가를 위해 사용된 지 수는 다음과 같다. 먼저 $\chi^{2}$ 의 값은 표본의 크기에 민감하므 로, 본 연구에서는 비교적 표본크기에 영향을 받지 않고, 모 형의 간명성을 고려하여 CFI, TLI와 SRMR, RMSEA를 이용 하였다(Bentler \& Bonett, 1980). 3요인 모형의 확인적 요인분 석 결과를 보면 $\left(\chi^{2}=126.221 ; d f=51, N=267, p<.001\right)$, CFI는 .93 , TLI는 .91로 나타나 좋은 적합도를 보였고, SRMR은 .05,

Table 4

The Model Fit Index of 3-Factor Final Model

\begin{tabular}{ccccccc}
\hline & $\chi^{2}$ & $d f$ & CFI & TLI & SRMR & RMSEA (90\% C.I.) \\
\hline Model & $126.22^{* * *}$ & 51 & .93 & .91 & .05 & $.07(.05-.09)$ \\
\hline
\end{tabular}

${ }^{* * *} p<.001$.

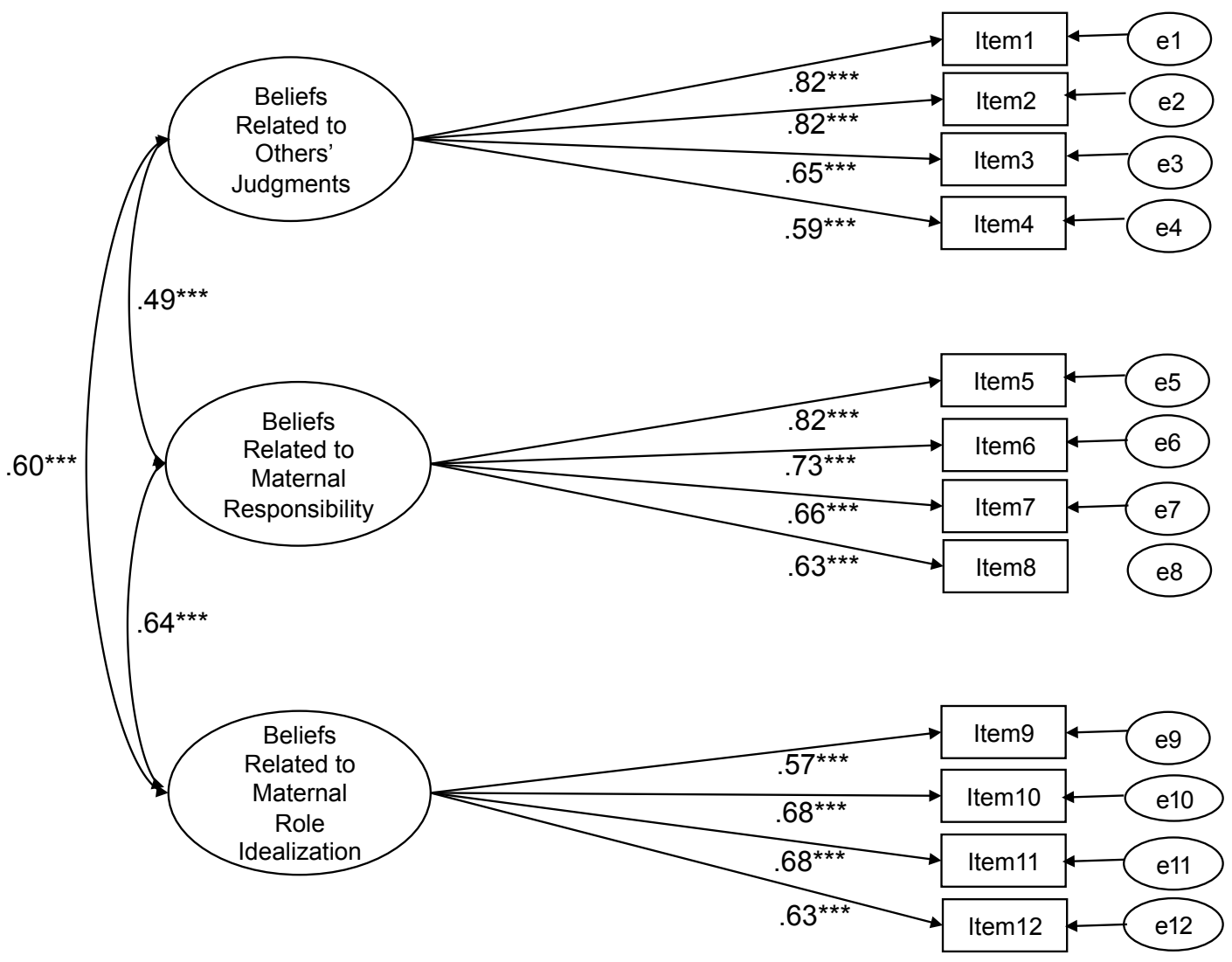

Figure 2. Standardized estimate of confirmatory factor analysis.

Note. $N=267$.

*** $p<.001$. 
Table 5

Correlations with Criterion-Related Scales

\begin{tabular}{|c|c|c|c|c|c|c|c|c|c|c|c|c|c|}
\hline & Variable & 1 & 2 & 3 & 4 & 5 & 6 & 7 & 8 & 9 & 10 & 11 & 12 \\
\hline \multirow[t]{3}{*}{ AToM } & 1. Total & - & & & & & & & & & & & \\
\hline & 2. Others' judgments & $.75^{* * *}$ & - & & & & & & & & & & \\
\hline & 4. Maternal role idealization & $.81^{* * *}$ & $.44^{* * *}$ & $.49^{* * *}$ & - & & & & & & & & \\
\hline GDA & 5. Total & $.56^{* * *}$ & $.61^{* * *}$ & $.33^{* * *}$ & $.39^{* * *}$ & - & & & & & & & \\
\hline \multirow[t]{4}{*}{ Stress } & 8. Total & $.38^{* * *}$ & $.43^{* * *}$ & $.23^{* * *}$ & $.23^{* * *}$ & $.47^{* * *}$ & $.44^{* * *}$ & $.41^{* * *}$ & - & & & & \\
\hline & 9. About fetal & $.34^{* * *}$ & $.42^{* * *}$ & $.20^{* * *}$ & $.19^{* * *}$ & $.45^{* * *}$ & $.43^{* * *}$ & $.38^{* * *}$ & $.83^{* * *}$ & - & & & \\
\hline & 10. About spouse & $.40^{* * *}$ & $.37^{* * *}$ & $.29^{* * *}$ & $.27^{* * *}$ & $.41^{* * *}$ & $.39^{* * *}$ & $.35^{* * *}$ & $.71^{* * *}$ & $.51^{* * *}$ & - & & \\
\hline & 11. About pregnant women & $.23^{* * *}$ & $.28^{* * *}$ & $.11^{* *}$ & $.15^{* * *}$ & $.31^{* * *}$ & $.29^{* * *}$ & $.29^{* * *}$ & $.85^{* * *}$ & $.51^{* * *}$ & $.41^{* * *}$ & - & \\
\hline
\end{tabular}

Note. $N=534$.

${ }^{* *} p<.01 .{ }^{* * *} p<.001$.

RMSEA는 .07로 양호한 적합도를 보였다. 따라서 문항분석과 탐색적 확인분석을 통해 도출해낸 AToM척도의 3요인 모형 및 해당 문항들은 적절한 것으로 확인되었다. 확인적 요인분 석 결과 모형의 적합도는 Table 4 와 같고, AToM 척도의 요인구 조를 Figure 2에 제시하였다. 3요인 구조의 요인부하량을 살펴 보면 다른 사람들의 판단에 대한 믿음이 .59 .82, 어머니의 책 임에 대한 믿음이 .63 .82, 어머니의 역할 이상에 대한 믿음이 .57 .68로 모두 .40이상의 값을 보여 적절한 문항들로 검증되 었다(Floyd \& Widaman, 1995).

\section{준거타당도 검증}

한국판 AToM 척도의 준거타당도를 확인하기 위해 1,2 차 표 본을 모두 이용해서 어머니됨에 대한 역기능적 태도와 이론적 으로 관련성을 갖는 일반적인 역기능적 태도, 임신기 스트레 스와 행복감과의 상관분석을 실시하였다. 분석결과는 Table 5 에 제시하였다. AToM 전체는 일반적인 역기능적 태도 전체 $(r$ $=.56, p<.001)$ 와 완벽주의 $(r=.57, p<.001)$, 의존 $(r=.42, p<$ .001) 하위 모두와 유의한 정적 상관을 보였고, 임신기 스트레 스 $(r=.38, p<.001)$ 의 태아관련 스트레스 $(r=.34, p<.001)$, 배 우자 관련 스트레스 $(r=.40, p<.001)$, 임부관련 스트레스 $(r=$ $.23, p<.001)$ 모두에서 유의한 정적 상관이 나타났다. 또한 행 복감과는 어머니의 책임에 대한 믿음을 제외한 요인들과 유 의한 부적 상관을 보였다( $r s=-.14 \sim-.33, p<.01)$. 행복감과 어 머니의 책임에 대한 믿음에서는 상관성이 나타나지 않았으
나, 행복감과 AToM 전체 문항의 상관이 유의하게 나타났고 다른 요인 간의 상관 또한 모두 유의하였다. 준거타당도의 경 우 일부 요인에서 상관이 낮게 나타나도 그 요인이 빠지면 구 성개념의 의미가 변할 수 있고, 다른 타당도의 결과가 양호하 다면 해당 변수를 제외하지 않고 사용할 수 있기 때문에(Woo, 2012) 어머니됨에 대한 역기능적 태도인 AToM 척도의 준거타 당성이 검증되었다고 볼 수 있다.

\section{Discussion}

본 연구에서는 Sockol 등(2014)이 개발한 어머니됨에 대한 역 기능적 태도(AToM) 척도를 한국어로 번역하고 임산부를 대상 으로 타당화 연구를 실시하였다. 본 연구결과를 토대로 논의 하면 다음과 같다.

첫째, 임산부 267 명을 1 차 표본으로 하여 문항분석과 탐색 적 요인분석을 실시한 결과, 문항분석의 기준에 걸리는 문항 이 하나도 없었고, 탐색적 요인분석결과도 본 척도와 마찬가 지로 최종 12 문항과 3 요인 구조가 적합한 것으로 나타났다. 즉 한국판 AToM 척도는 다른 사람들의 판단에 대한 믿음 $(4$ 문항), 어머니의 책임에 대한 믿음(4문항), 어머니의 역할 이 상에 대한 믿음(4문항)의 3요인 구조로 나타났다. AToM 척도 는 2014년도에 개발된 것으로 아직 다른 나라에서의 타당화 연구는 거의 이루어지지 않은 상태이다. 현재는 포르투갈에 서 진행된 타당화 연구(Costa, Rodrigues, Canavarro, \& Fonseca, 
2018)가 유일한데, 이 연구에서는 문항 12 번(“내가 엄마가 되 는 것에 실패하면, 나는 한 인간으로서 실패한 것이다.”)이 요 인 3(어머니의 역할 이상에 대한 믿음)이 아니라 요인 2(어머 니의 책임에 대한 믿음)에 포함되는 것으로 나타나서 원척도 및 본 연구결과와 다소 다른 결과를 보였다. 어머니의 책임에 대한 믿음 요인은 어머니의 행동적인 책임을 강조하는 것이 고, 어머니의 역할 이상에 대한 믿음 요인은 어머니됨에 대한 임산부 자신의 정서적 평가를 강조하는 것이다. 이러한 차이 를 볼 때, Costa 등(2018)은 12 번 문항의 차이를 연구대상자의 대부분이 직장인으로서 사회적으로 상위층에 속하는 여성들 이기 때문으로 보았다. 즉 사회적으로 성공한 여성일수록 어 머니가 되는 것을 정서적인 만족감의 측면으로 보기보다, 여 성의 의무와 책임으로 보는 관점이 더 강하기 때문에 문항 12 번이 요인3이 아닌 요인2에 속하게 되는 것으로 설명하였다. 하지만 본 연구의 대상자들은 취업중인 자와 미취업자가 각각 $50 \%$ 로 원척도와 마찬가지로 동일한 요인구조를 가지는 것으 로 나타났다. 이처럼 동일한 도구일지라도 대상자의 특성 및 나라의 사회문화적 배경의 차이로 인해 최종 추출된 문항이 다를 수 있다(Golbasi, Ucar, \& Tugut, 2015). 따라서 추후 연구 에서는 대상자의 나라, 취업유무, 임신한 자녀의 출생순위 등 과 같은 특성에 따른 차이를 보고, 그에 따른 타당화 연구를 진 행할 필요가 있다.

둘째, 확인적 요인분석과 신뢰도분석을 통해 AToM 척도의 3 요인 구조의 적합성과 신뢰도 지수를 살펴본 결과, 3 요인 모 형의 적합도 $\left(\chi^{2}=126.221 ; d f=51, N=267, p<.001\right)$ 는 CFI .93, TLI .91로 나타나 좋은 적합도를 보였고, RMSEA도 .07 (90\% 신뢰구간: .58 .09)로 양호하였으며, SRMR도 .05로 적절한 적합도를 보였다(Bentler \& Bonett, 1980). 최종척도에 대한 내 적합치도(Cronbach's $\alpha$ )는 .86으로 좋은 신뢰도를 나타냈으며, 각 요인의 내적합치도(Cronbach's $\alpha$ )는 다른 사람들의 판단에 대한 믿음 .86 , 어머니의 책임에 대한 믿음 .81 , 어머니의 역할 이상에 대한 믿음 .78 로 신뢰도가 높게 나타났다. 반분신뢰도 또한 각 하위요인이 $.80, .80, .83$ 로 우수한 값으로 나타나 전체 적으로 높은 신뢰도를 가진 것으로 검증되었다. 이를 통해 본 연구에서 타당화한 '한국판 어머니됨에 대한 역기능적 태도' 척도가 신뢰할 수 있는 척도임을 알 수 있다.

셋째, AToM 척도의 준거타당도를 검증하고자 선행연구와 이론적 관련성을 갖는 일반적인 역기능적 신념, 임신기 스트 레스, 행복감과의 상관분석을 실시하였다. 먼저 AToM과 일반 적인 역기능적 신념의 상관을 살펴보면, 모든 하위요인 간에 정적상관이 있는 것으로 나타났는데, 이는 선행연구(Fonseca et al., 2018)와 일치하는 결과이다. 완벽주의적이고 타인의 평 가에 민감하며 타인에게 과도하게 의존하는 등의 특징을 가 진 이들은 기본적으로 자신과 미래, 타인에 대한 부정적인 인 식을 가지고 있고, 완벽하지 않으면 실패한 것으로 간주하는 등의 편향된 태도를 지닌다(de Graaf et al., 2009). 이는 임신기 에 어머니됨에 대한 인식에 똑같이 적용되어 어머니됨에 대 해서도 완벽함을 요구하고 그렇지 않을 경우 타인이 자신을 부정적으로 평가할 것이란 잘못된 신념으로 이어진다. 이러 한 역기능적인 태도들은 우울과 불안 등과 같은 내재화 장애 와 깊은 상관관계를 보이므로(Halvorsen, Wang, Eisemann, \& Waterloo, 2010) 정서적 건강을 위해서 이러한 인지적인 편향 을 줄일 수 있는 방법에 대한 연구가 필요하다. 또한 AToM의 하위요인과 임신기 스트레스의 모든 하위요인들이 유의한 정 적 상관이 있는 것으로 나타났다. 즉 어머니됨에 대한 완벽주 의적이고 이상적인 태도가 높으면 임신기에 느끼는 태아와 자 신 및 배우자에 대한 걱정으로 인한 스트레스 또한 높다는 것 을 알 수 있다. 어머니됨에 대한 역기능적 태도를 지닌 이들은 회피나 부정, 신체화 등과 같은 성숙하지 못한 스트레스 대처 방식을 사용하기 때문에(Milgrom \& Beatrice, 2003), 이런 태도 를 지닌 이들에게서 임신기 스트레스는 더욱 높을 것으로 해 석할 수 있다. 마지막으로 어머니됨에 대한 역기능적 태도와 행복감에서는 어머니의 책임에 대한 믿음 요인만을 제외한 모 든 하위요인에서 유의한 부적 상관이 나타났다. 즉 자신의 양 육방식과 아이를 대하는 행동에 대한 다른 사람들의 평가에 민감하게 반응하고, 자신이 완벽하지 않으면 다른 이들이 자 신을 비난할 것이라고 생각한다면 개인의 삶에 대한 전반적 인 행복감이 낮아질 수 있음을 말해준다. 이는 관련 선행연구 와 일치하는 결과로, 타인의 평가에 대한 잘못된 믿음은 대인 관계에서의 어려움을 가져오고, 우울 및 불안, 성격장애 등 다 양한 심리적 문제와 관련이 있어서 궁극적으로 개인의 행복감 과 주관적 안녕감을 떨어뜨린다(Ha \& Jang, 2011). 특히 이러 한 완벽주의 성향의 사람들은 의미 있는 타인으로부터 인정 과 사랑을 받고자 하는 욕구가 커서 타인의 높은 기준에 도달 하려고 노력하나, 이는 가시적인 확인이 불가능하고 스스로가 통제할 수도 없기 때문에 결국 좌절과 불안과 같은 부정적인 정서를 일으켜 삶의 질을 떨어뜨리는 것으로 볼 수 있다(Hur, 2004). 반면 어머니의 책임에 대한 믿음 요인과 행복감과는 유 의한 상관이 나타나지 않았는데, 이는 대상자가 임산부이기 때문으로 보인다. 해당 하위요인의 문항 내용들은 주로 아이 가 태어난 후에 자신이 아이에게 헌신해야한다는 내용들로 이 루어져있다. 이는 출산 후에 실제로 아이에게 헌신하지 못할 
때 큰 스트레스를 받을 수는 있겠지만, 임신기에는 아직 그런 상황이 나타나기 이전 시기로 그로 인한 불안과 걱정은 있겠 지만 개인의 행복감에 미치는 영향까지는 없는 것으로 보인 다. 이를 제외한 AToM 척도와 이론적으로 관련이 있는 모든 준거 변인들과의 상관이 유의하게 나타났으므로 한국판 어머 니됨에 대한 역기능적 태도의 준거타당도가 확보되었다고 볼 수 있다.

앞서 말한 결과를 통해 나타난 본 연구의 시사점과 의의는 다음과 같다. 첫째, 어머니됨에 대한 역기능적 태도(AToM) 척 도를 한국어로 번역하고 한국의 임산부들을 대상으로 타당화 연구를 실시하여 우수한 신뢰도와 타당도를 확보하였다는 것 에 의의가 있다. 최근 한국 사회는 타인의 평가에 매우 민감하 고 체면을 중시하며, 경쟁에 대한 스트레스가 큰 특성을 보이 는데, 이러한 특성으로 인해 어머니됨에 대해서도 타인의 평 가를 극도로 신경 쓰고, 완벽해야한다는 역기능적인 태도가 부모의 양육신념 및 행동에 큰 영향을 미칠 수 있다. 따라서 한 국 임산부를 대상으로 임신기의 어머니됨에 대한 태도를 측 정하는 것은 의미 있는 일이다. 둘째, 본 연구에서 타당화한 $\mathrm{AToM}$ 척도를 활용해 임상, 심리, 간호 등 다양한 분야에서 관 련 연구를 수행할 수 있을 것이고, 어머니됨에 대한 역기능적 태도가 강한 임산부들을 대상으로 산후우울을 예방할 수 있는 치료나 개입을 할 때에도 활용할 수 있을 것이다. 특히 본 연구 대상이 임산부인 만큼 임산부를 대상으로 한 산후우울 예방교 육을 개발할 때, 본 연구 결과를 활용하여 임산부의 어머니됨 에 대한 역기능적 태도를 알아보고 보다 순기능적인 태도로 변화할 수 있는 내용을 포함시킬 수 있을 것이다. 셋째, 준거타 당도 검증을 통해 어머니됨에 대한 역기능적 태도가 일반적인 역기능적 태도와 임신기 스트레스, 그리고 행복감과 유의한 상관이 있다는 것을 밝혔는데, 이는 어머니됨에 대한 태도와 다른 심리적 요인과의 관련성을 밝히는 연구를 수행할 수 있 는 기초자료가 될 것이다.

이러한 의의에도 불구하고 본 연구의 제한점을 토대로 후 속연구에 대한 제언을 하면 다음과 같다. 첫째, 본 연구 대상자 는 서울·경기지역의 임산부 교육에 참여한 임산부들만을 대 상으로 한 것으로 사회인구학적 배경이 다양하지 않고, 특히 자발적으로 임산부 교육에 참석한 사람들이므로 이 결과를 일 반화하는 데에 한계가 있을 수 있다. 추후 연구에서는 보다 다 양한 사회인구학적 배경을 가지고, 양육과 교육에 대한 관심 수준이 다양한 예비부모를 대상으로 연구가 이루어질 필요가 있다. 둘째, AToM 척도는 임산부를 대상으로 개발된 것이지 만 어머니됨에 대한 역기능적 태도는 출산 후에도 지속되어
어머니의 정신건강과 아이 발달에 영향을 미칠 수 있으므로 추후 연구에서는 출산 이후의 어머니됨에 대한 역기능적 태도 를 측정할 수 있는 척도의 개발과 타당화 연구 또한 필요하다. 셋째, 본 연구는 횡단연구로 임신기 동안 어머니의 역기능적 태도를 측정하였으나, 추후연구에서는 산전 AToM 척도점수 가 출산 후 우울에 미치는 영향에 대한 종단연구가 이루어져 야할 것이다.

\section{Conflict of Interest}

No potential conflict of interest relevant to this article was reported.

\section{References}

\section{In English}

Beck, A. T. (1972). Depression: Causes and treatment. Philadelphia, PA: University of Pennsylvania Press.

Beck, J. V., Blackwell, B., \& Clair Jr, C. R. S. (1985). Inverse heat conduction: Ill-posed problems. New York: John Wiley \& Sons.

Bentler, P. M., \& Bonett, D. G. (1980). Significance tests and goodness of fit in the analysis of covariance structures. Psychological Bulletin, 88(3), 588-606. doi:10.1037/0033-2909.88.3.588

Church, N. F., Brechman-Toussaint, M. L., \& Hine, D. W. (2005). Do dysfunctional cognitions mediate the relationship between risk factors and postnatal depression symptomatology? Journal of Affective Disorders, 87(1), 65-72. doi:10.1016/j.jad.2005.03.009

Costa, A. C., Rodrigues, S., Canavarro, M. C., \& Fonseca, A. (2018). Adaptaçáo da escala de crenças disfuncionais face à maternidade para a população portuguesa: Estudos psicométricos. Análise Psicológica, 36(2), 247-260. doi:10.14417/ap.1387

Costello, A. B., \& Osborne, J. W. (2005). Best practices in exploratory factor analysis: Four recommendations for getting the most from your analysis. Practical Assessment, Research \& Evaluation, 10(7), 1-9.

de Graaf, L. E., Roelofs, J., \& Huibers, M. J. H. (2009). Measuring dysfunctional attitudes in the general population: The dysfunctional attitude scale (form A) revised. Cognitive Therapy and Research, 33, 345-355. doi:10.1007/s10608-009-9229-y

Dimidjian, S., Goodman, S. H., Felder, J. N., Gallop, R., Brown, A. P., \& Beck, A. (2016). Staying well during pregnancy and the postpartum: A pilot randomized trial of mindfulness- 
based cognitive therapy for the prevention of depressive relapse/recurrence. Journal of Consulting and Clinical Psychology, 84(2), 134-145. doi:10.1037/ccp0000068

Eagly, A. H., \& Chaiken, S. (2007). The advantages of an inclusive definition of attitude. Social Cognition, 25(5), 582-602. doi:10.1521/soco.2007.25.5.582

Floyd, F. J., \& Widaman, K. F. (1995). Factor analysis in the development and refinement of clinical assessment instruments. Psychological Assessment, 7(3), 286-299.

Fonseca, A., Monteiro, F., \& Canavarro, M. C. (2018). Dysfunctional beliefs towards motherhood and postpartum depressive and anxiety symptoms: Uncovering the role of experiential avoidance. Journal of Clinical Psychology, 74(12), 2134-2144. doi:10.1002/jclp.22649

Frisbie, D. A., \& Ebel, R. L. (1972). Comparative reliabilities and validities of true-false and multiple choice tests. Retrieved from ERIC database. (ED064388)

Golbasi, Z., Ucar, T., \& Tugut, N. (2015). Validity and reliability of the Turkish version of the maternal antenatal attachment scale. Japan Journal of Nursing Science, 12(2), 154-161. doi:10.1111/jjns. 12052

Halvorsen, M., Wang, C. E., Eisemann, M., \& Waterloo, K. (2010). Dysfunctional attitudes and early maladaptive schemas as predictors of depression: A 9-year follow-up study. Cognitive Therapy and Research, 34(4), 368-379. doi:10.1007/s10608-009-9259-5

Hayton, J. C., Allen, D. G., \& Scarpello, V. (2004). Factor retention decisions in exploratory factor analysis: A tutorial on parallel analysis. Organizational Research Methods, 7(2), 191-205. doi:10.1177/1094428104263675

Horn, J. L. (1965). A rationale and test for the number of factors in factor analysis. Psychometrica, 30(2), 179-185.

Kline, R. B. (2015). Principles and practice of structural equation modeling (4th ed.). New York: The Guilford Press.

Milgrom, J., \& Beatrice, G. (2003). Coping with the stress of motherhood: Cognitive and defence style of women with postnatal depression. Stress and Health, 19(5), 281-287. doi:10.1002/smi.986

Milgrom, J., Martin, P. R., \& Negri, L. M. (1999). Treating postnatal depression: A psychological approach for health care practitioners. New York: John Wiley \& Sons.

Moorhead, S. R. J., Owens, J., \& Scott, J. (2003). Development and piloting of the Pregnancy Related Beliefs Questionnaire (PRBQ). Behavioural and Cognitive Psychotherapy, 31(2), 207-213. doi:10.1017/S1352465803002091

Mplus (Version 7.4). [Computer software]. Los Angeles, CA: Muthén \& Muthén.

Page, T., Combs-Orme, T., \& Cain, D. S. (2007). New mothers' psychological experience and behavioral interactions with their infants in the first 12 months. Journal of Child and
Family Studies, 16(2), 155-167. doi:10.1007/s10826-0069075-4

Phillips, J., Sharpe, L., Matthey, S., \& Charles, M. (2010). Subtypes of postnatal depression? A comparison of women with recurrent and de novo postnatal depression. Journal of affective disorders, 120(1-3), 67-75. doi:0.1016/j.jad.2009.04.011

Sockol, L. E. (2008). Predicting depressive symptoms during pregnancy: Integrating cognitive, coping and social perspectives (Master's thesis).

Sockol, L. E., \& Battle, C. L. (2015). Maternal attitudes, depression, and anxiety in pregnant and postpartum multiparous women. Archives of Women's Mental Health, 18(4), 585-593. doi:10.1007/s00737-015-0511-6

Sockol, L. E., Epperson, C. N., \& Barber, J. P. (2014). The relationship between maternal attitudes and symptoms of depression and anxiety among pregnant and postpartum first-time mothers. Archives of Women's Mental Health, 17(3), 199-212. doi:10.1007/s00737-014-0424-9

Thomason, E., Flynn, H. A., Himle, J. A., \& Volling, B. L. (2015). Are women's parenting-specific beliefs associated with depressive symptoms in the perinatal period? Development of the rigidity of maternal beliefs scale. Depression and Anxiety, 32(2), 141-148. doi:10.1002/da.22280

Warner, R., Appleby, L., Whitton, A., \& Faragher, B. (1997). Attitudes toward motherhood in postnatal depression: Development of the maternal attitudes questionnaire. Journal of Psychosomatic Research, 43(4), 351-358. doi:10.1016/S00223999(97)00128-1

Woolhouse, H., Gartland, D., Perlen, S., Donath, S., \& Brown, S. J. (2014). Physical health after childbirth and maternal depression in the first 12 months post partum: Results of an Australian nulliparous pregnancy cohort study. Midwifery, 30(3), 378-384. doi:10.1016/j.midw.2013.03.006

\section{In Korean}

Ahn, H.-L. (1983). A pilot study of stressor and stress situation and nursing intervention of pregnant women. Journal of Korean Academy of Nursing, 13(3), 75-85.

Choi, Y. (2002). (The) effect of mood awareness on happiness (Master's thesis). Retrieved from http://www.riss.kr/link?id= T8367006

Ha, J. H., \& Jang, Y. J. (2011). The relations of perfectionism to subjective well-being and perceived social support giving among college students: Received social support as a mediator. The Korean Journal of Counseling and Psychotherapy, 23(2), 427-449.

Hur, H. J. (2004). The effect of perfectionism on subjective well-being; Mediated by inferiority (Master's thesis). Retrieved from http://www.riss.kr/link?id=T9502010 
Kim, Y. R. (2009). The effects of a poomassi parent self-help activity on parenting stress, family empowerment, and family quality of life in mothers of children with disabilities (Master's thesis). Retrieved from http://www.riss.kr/link?id=T11551557

Kim, E. H., Rhee, S. H., Lee, W. K., Kim, M., \& Doh, H.-S. (2017). A grounded theory study on first-time pregnant couples' adaptation processes to parenthood. Korean Journal of Family Welfare, 22(1), 1-39. doi:10.13049/ kfwa.2017.22.1.1

Woo, J. (2012). Woojongpil gyosuui gujobangjeongsingmodel gaenyeomgwa ihae: Amos 4.0 20.0 gongyong [우종필 교수 의 구조방정식모델 개념과 이해: Amos 4.0 20.0 공용]. Seoul: Hannarae.

\section{ORCID}

Hae-Mi Kim https://orcid.org/0000-0003-4904-7259

Su-Kyoung Kang https://orcid.org/0000-0001-7919-4335

Received June 28, 2019

Revision received August 5, 2019

Accepted August 7, 2019 